\title{
A posição-sujeito gramático ocupada por Evanildo Bechara na mídia: tradição e/ou modernidade?
}

\section{The subject-position grammarian used by Evanildo Bechara in the media: tradition and/or modernity?}

\author{
Agnaldo Almeida \\ agnaldoal@hotmail.com \\ Universidade Federal de Minas Gerais
}

Resumo: No presente trabalho, buscamos analisar o modo de funcionamento da posição-sujeito gramático ocupada por Evanildo Bechara na mídia. Pautamo-nos no arcabouço teórico da Análise de Discurso de linha francesa, de viés pecheutiano, e da História das Ideias Linguísticas. Consideramos que o sujeito é uma posição discursiva, entre outras, inscrita em dadas formações discursivas que, por sua vez, são determinadas por formações ideológicas. Logo, o que se diz não é dito de qualquer lugar, em qualquer circunstância. Enquanto sujeito gramático, posição construída sócio-historicamente, Evanildo Bechara pode enunciar de diferentes lugares, tais como o da tradição e o da ciência. Questionamo-nos, então: qual a posição-sujeito assumida pelo sujeito em questão? É reproduzido um discurso purista, pautado no tradicionalismo, ou há um deslizamento para uma posição científica, que leva em consideração os "avanços" dos estudos linguísticos? Para tanto, tomamos como corpus entrevistas com tal gramático postas em circulação pela mídia nacional entre os anos de 2005 a 2013. Em nossas análises, observamos que o sujeito em questão funciona em uma relação de distanciamento à imagem do gramático tradicional, aquele que não leva em conta os "avanços" dos estudos linguísticos. Porém, os sentidos 
destes "avanços" encontram-se em uma relação contraditória com aqueles advindos da tradição gramatical. São reiteradas imagens e valores de que existe, por exemplo, um "bom português" e de que o domínio da norma culta é um dos requisitos fundamentais para a ascensão social. Portanto, enuncia-se sobre os "avanços" dos estudos linguísticos a partir da posição-sujeito gramático tradicional.

Palavras-chave: posição-sujeito; mídia; gramático.

Abstract: In this paper, we analyze the operating mode of positionsubject grammarian used by Evanildo Bechara in the media. Guided by the theoretical framework of French Discourse Analysis, pecheutiano influence, and the History of Ideas Linguistic, we consider the subject a discursive position, among others, registered in given discursive formations which, in turn, are determined by ideological formations. So, what is said is not said anywhere, under any circumstances. While subject grammarian position built socio-historically Evanildo Bechara may contain from different places, such as from tradition and science. We wonder, then, what is the subject-position assumed by the subject in question? A purist discourse, based in traditionalism is played, or there is a slip for a scientific position, which takes into account the "advances" of linguistic studies? To this end, we take as corpus interviews with such grammarian put into circulation by the national media around the years 2005 to 2013. In our analysis, we observed that the subject matter works in a distance relationship to the image of the traditional grammarian, one that does not take into account the "advances" of linguistic studies. But, the mean these "advances" find themselves in a contradictory relationship with those coming from the grammatical tradition. Images and values are repeated that is real, for example, a "good Portuguese" and the field of cultural norms is a fundamental requirement for social mobility. So is necessary enunciate on the "advances" of linguistic studies from the position subject-traditional grammarian.

Keywords: subject-position; media; grammarian.

Recebido em: 1 de julho de 2015. Aprovado em: 25 de abril de 2016. 


\section{Primeiras palavras}

Conforme Orlandi (2000a) e Guimarães (1996a), até meados do século XIX, os estudos da língua portuguesa realizados no Brasil consistiam em uma apropriação de nosso país por Portugal, porque não havia trabalhos sobre as especificidades do português brasileiro. É na segunda metade do século XIX, atrelados à questão da independência nacional e à constituição de uma língua nacional, que tais estudos começam a se desenvolver de modo particular, com a elaboração e publicação de gramáticas de autoria brasileira. Estas procuravam atender ao Programa de português para os exames preparatórios, elaborado por Fausto Barreto.

O gramático, nesse contexto, tem uma dupla função: intelectual e política. Cabe a este sujeito o estabelecimento de uma unidade linguística (língua nacional), deslocando a autoridade de quem deve dizer como é a nossa língua e sua metalinguagem, que deixa de ser uma mera repetição do saber gramatical português. O gesto de autoria dos primeiros gramáticos brasileiros (Júlio Ribeiro, João Ribeiro etc.) está diretamente vinculado à constituição do Estado e de uma identidade linguística, cidadã e nacional. É inaugurada uma posição-sujeito gramático brasileiro, um lugar “[...] onde se produz um conhecimento legítimo da língua que corresponde a um gesto de apropriação da própria língua" (ORLANDI, 2000b, p. 30).

No século seguinte, segundo Orlandi (2000a), as condições de produção mudam e, consequentemente, o funcionamento da autoria gramatical. O Estado em si marca as nossas diferenças em relação a Portugal. A gramática deixa de ter a função de atribuir forma aos limites da identidade brasileira. Porém, aflora uma profusão desse instrumento linguístico, tecnologia que representa a língua para seus sujeitos falantes (AUROUX, 2009), e de terminologias, apagando a materialidade da autoria estabelecida no século anterior. Assim, em 1959, é instituída a Nomenclatura Gramatical Brasileira (NGB), cujo objetivo é homogeneizar as partes e nomenclaturas das gramáticas; em 1965, por meio de um decreto, o Conselho Nacional de Educação torna a Linguística uma disciplina obrigatória nos cursos de Letras do Brasil.

Com estes deslocamentos, a autoria passa a funcionar de modo diferente, ocorre uma transferência do conhecimento do gramático para o linguista, um "[...] deslizamento cada vez mais forte de uma posição política e intelectual para uma posição marcadamente científica da 
questão posta pela língua" (ORLANDI, 2000a, p. 30). A cientificidade torna-se um argumento para a afirmação de nossa identidade, e a gramática deixa de ser um monumento à língua para se apresentar como um artefato de ciência.

No presente trabalho, buscamos compreender o modo de funcionamento da posição-sujeito gramático ocupada pelo gramático Evanildo Bechara. Metodologicamente, adotamos a abordagem qualitativa, por conta da natureza do resultado buscado. Desse modo, foram selecionadas 10 entrevistas, quantidade máxima encontrada na internet, com o gramático em questão, postas em circulação pela mídia nacional (jornais, revistas semanais, periódicos, sites institucionais etc.), entre os anos de 2005 a 2013. Questionamo-nos, então: como se constitui a posição-sujeito assumida pelo sujeito em questão? É reproduzido um discurso purista, pautado no tradicionalismo, ou há um deslizamento para uma posição científica, que leva em consideração os "avanços" dos estudos linguísticos?

Para responder tais questões, respaldamo-nos nos trabalhos realizados na área de História das Ideias Linguísticas no Brasil, ao considerar constitutiva a relação entre a história da língua e a história de seu saber linguístico. Articulamos essa área aos pressupostos da Análise de Discurso de linha francesa, de viés pecheutiano, para a qual o sujeito, a língua e os sentidos não são transparentes, eles têm uma materialidade constitutiva. Sujeitos e sentidos se constituem ao mesmo tempo por um processo que tem como fundamento a ideologia. E a língua, em sua forma material, na medida em que é suscetível à falha, ao deslize, ao equívoco, é lugar para a interpretação.

Em nossas análises, constatamos que o sujeito em questão é construído no distanciamento em relação à imagem do gramático tradicional, aquele que não leva em conta os "avanços" dos estudos linguísticos. Ao analisar as discursividades, verificamos que é requerida a caução da Linguística para a inscrição do trabalho gramatical nas práticas científicas. Como a relação entre a tradição gramatical e os "avanços" dos estudos linguísticos é contraditória, compreendemos os sentidos desses "avanços" enquanto uma exterioridade constitutiva que afeta o sujeito e o faz funcionar. Evanildo Bechara, ao ocupar a posição-sujeito gramático, se constitui nesse jogo tenso e conflituoso. 


\section{Política linguística e gramatização do português no brasil}

Apoiando-nos na teoria materialista do discurso, a qual procura analisar as determinações históricas dos processos de significação, observamos que a materialidade do sentido resulta de um processo histórico de significação em que o sujeito, a história e a linguagem estão materialmente pensados e implicados (ORLANDI, 2009). Enquanto sujeitos, somos afetados pelo real da língua e pelo real da história, não tendo controle de como eles nos afetam. A constituição de um saber (meta) linguístico está diretamente atrelada à constituição de uma identidade nacional, linguística e cidadã daqueles que falam uma determinada língua.

De acordo com Auroux (2009), o processo de gramatização é decisivo para a constituição do saber metalinguístico de uma sociedade. A gramatização é, consoante tal autor $(2009$, p. 65), “[...] o processo que conduz a descrever e a instrumentar uma língua na base de duas tecnologias, que são ainda hoje os pilares de nosso saber metalinguístico: a gramática e o dicionário". É uma transferência tecnológica de uma língua para outras, sendo que os sujeitos responsáveis pela transferência podem ser ou não locutores nativos das línguas em que esse processo é desencadeado. Nos termos do autor, enquanto a endogramatização é efetuada por sujeitos nativos, a exogramatização é realizada por sujeitos não nativos da língua em que ocorre a transferência.

O processo de gramatização dos vernáculos europeus transcorre do século V ao século XIX. Contudo, é a partir do final do século XV que ocorre a gramatização massiva das línguas europeias, como francês, português, espanhol e italiano, decorrente de três elementos fundamentais: a renovação da gramática latina - há uma recusa à gramática latina medieval pelos humanistas, que buscam a restauração do latim clássico, considerado belo; a imprensa, que permite a multiplicação do mesmo texto, diminuindo o seu custo, e o aumento de sua difusão; e as grandes descobertas - de cunho territorial (grandes navegações) e científico. Este processo está vinculado à constituição das nações europeias e as suas respectivas transformações nas relações sociais, como o nascimento do capital mercantil, a mobilidade social, a urbanização etc.

O período do Renascimento Europeu (XIV a XVI) é fecundo para a gramatização. Desenvolve-se uma intensa produção de gramáticas e dicionários, tendo como base uma única tradição linguística europeia (a greco-latina). E para a consolidação desse processo, a produção de 
gramáticas é de suma importância, em razão de ela ser uma descrição linguística, um corpus de afirmações que propõem "reduzir" a língua a regras. A gramatização busca a redução das variantes linguísticas apoiando-se nas regras do "bom uso". A gramática é, nesse viés, um instrumento linguístico. Ela, conforme Auroux,

[...] não é uma simples descrição da linguagem natural; é preciso concebê-la também como instrumento linguístico: do mesmo modo que um martelo prolonga o gesto da mão, transformando-o, uma gramática prolonga a fala natural e dá acesso a um corpo de regras e de formas que não figuram juntas na competência de um mesmo locutor (AUROUX, 2009, p. 70).

Destarte, as práticas linguísticas se transformaram com o surgimento dos instrumentos linguísticos. Auroux (2009) afirma que uma língua é gramatizada quando podemos aprendê-la (falar/escrever), por meio desses instrumentos. Como a gramática greco-latina é utilizada como base para a constituição das gramáticas europeias, retomam-se as categorias de suas partes do discurso, mesmo que não existam na língua em processo de gramatização.

No Brasil, retomando a classificação postulada por Auroux (2009), houve, inicialmente, a exogramatização. Os instrumentos gramaticais europeus foram impostos aos índios e outros povos que aqui habitavam por indivíduos não nativos, os portugueses. É com a questão da língua nacional no Brasil, a partir da segunda metade do século XIX, que "o Brasil tem seus próprios instrumentos linguísticos de gramatização, diferentes de Portugal” (ORLANDI; GUIMARÃES, 2001, p. 24).

É a partir deste momento que os estudos das ideias linguísticas e a gramatização se desenvolveram de um modo específico aqui no Brasil, evidenciando que o português aqui falado e escrito era diferente do de Portugal. No Português brasileiro, temos palavras de origem africanas e indígenas, além de algumas significarem diferentemente. Antes desse século, ressaltam Guimarães e Orlandi (1996b), a questão da linguagem era apenas uma forma de apropriação do Brasil pela Europa, pois as gramáticas e dicionários aqui produzidos, até esse momento, não tratavam de nossas especificidades. Por uma abordagem histórica, Guimarães (1996a) divide a gramatização do português no Brasil em quatro períodos. 
O primeiro período tem início em 1500 , com a colonização, e prolonga-se até a primeira metade do século XIX, quando ocorrem debates entre brasileiros e portugueses sobre algumas construções consideradas inadequadas do português. Os anos finais dessa época coincidem com a Independência do Brasil, que abre questões importantes, como a constituição de uma língua nacional.

O segundo momento se estende da segunda metade do século XIX, a partir dos debates travados no final do período anterior e pela publicação de gramáticas, como a de Júlio Ribeiro, em 1881, até o fim dos anos 1930, com a fundação das Faculdades de Letras no Brasil. Em sua Gramática Portuguesa, Júlio Ribeiro se distancia das gramáticas portuguesas, buscando influência em teóricos de outros países. A publicação dessa gramática é o marco inicial para o período de gramatização aqui no Brasil. Surgem outras gramáticas importantes nos anos subsequentes, cujo objetivo era atender ao novo Programa de português para exames preparatórios, elaborado por Fausto Barreto ${ }^{1}$.

Alguns escritores têm a preocupação de que devemos escrever como falamos no Brasil, e não como se escreve em Portugal. Segundo Orlandi (2000a, p. 27), nesta época, "ser autor de uma gramática é ter um lugar de responsabilidade como intelectual e ter uma posição de autoridade em relação à singularidade do português no Brasill”. O saber metalinguístico defendido pelo gramático brasileiro não é, desse modo, um mero reflexo do saber gramatical português. Além de saber sua língua, os brasileiros necessitavam de um suporte institucional para mostrar que a sabem. A gramática é esse lugar material, tornando-se um saber legítimo para a sociedade.

O gesto de autoria dos primeiros gramáticos brasileiros (Júlio Ribeiro, João Ribeiro, entre outros) está diretamente ligado à construção do Estado e de uma identidade do brasileiro. Língua e Estado se conjugam: "[...] a identidade linguística, a identidade nacional, a

\footnotetext{
${ }^{1}$ De acordo com Fávero (2001, 2007), Ś́lvio Elia divide a história dos estudos gramaticais no Brasil em dois períodos: o vernaculista, de 1820, época de nossa independência, a 1880, quando é publicada a Gramática Portuguesa de Júlio Ribeiro, marco do segundo período: o científico. Enquanto no primeiro a gramática é considerada uma arte, remontando a conceituação advinda do modelo greco-latino, o período subsequente é marcado pela adesão ao método científico, buscando contemplar o Programa elaborado por Fausto Barreto.
} 
identidade do cidadão na sociedade brasileira traz entre os componentes de sua formação a constituição (autoria) de gramáticas brasileiras no século XIX" (ORLANDI, 2000a, p. 28). É ainda desse período, 1897, a fundação da Academia Brasileira de Letras - ABL. Instituição que se envolve em acordos de unificação ortográfica e emerge com o intuito de "cultivar a língua e a literatura nacional".

O terceiro período, por sua vez, transcorre do final dos anos 1930 até meados da década de 1960, quando a Linguística é institucionalizada como uma disciplina obrigatória nos cursos de Letras. A fundação das Faculdades de Letras representa a abertura de um espaço para discutir questões de linguagem. Em 1943, é estabelecida a ortografia da língua portuguesa no Brasil, por meio de um acordo ortográfico, com algumas diferenças em relação à ortografia de Portugal. É discutida a nomenclatura que deveria ter a língua falada no Brasil e concluído que continuaria a ser chamada de língua portuguesa. Em 1959 foi sancionada a Nomenclatura Gramatical Brasileira - NGB, com o objetivo de definir e padronizar as terminologias e partes das gramáticas aqui produzidas.

Orlandi (2000b) e Baldini (1998) argumentam que a imposição da NGB gera uma nova relação dos gramáticos com a autoria, uma vez que eles passam de autores para comentadores de tal documento: "os próprios títulos das gramáticas lançadas em seguida materializam esse acontecimento: as gramáticas exemplificam, definem, interpretam e explicam a NGB. O gramático passa a ser aquele que comenta a nomenclatura" (BALDINI, 1998, p. 101). Desde então, as gramáticas escolares a adota consistentemente, mesmo não havendo referências explícitas nas gramáticas atuais.

Já o quarto período desenrola-se de 1965 até hoje, marcado pela implantação da Linguística em todos os cursos de Letras e o surgimento de cursos de Pós-Graduação. Guimarães (1996a) pondera que esse período tem diversas linhas de pesquisa em relação ao português: trabalhos gramaticais de cunho estrutural, funcional ou gerativo; trabalhos semânticos, sendo eles formais ou enunciativos; trabalhos de sociolinguística (variacionista, interacionista etc.); trabalhos em análise do discurso, os quais se debruçam sobre o funcionamento discursivo do português no Brasil; etc. Consoante Orlandi (2000a), observa-se um deslizamento da posição intelectual e política dos gramáticos do século XIX para uma posição mais científica, respaldada pelos estudos linguísticos. 
O modo de organização histórica dos estudos sobre o Português segue dois caminhos diferentes, observado que "um mesmo gramático, linguista, filólogo pode ter na sua obra, ou num mesmo texto, a presença dos dois recortes" (GUIMARÃES, 1996a, p. 134). Consoante o autor, o primeiro recorte é composto por estudos que visam evidenciar (de forma contrastiva ou não) a especificidade do português brasileiro do de Portugal. Em meados do século XIX, essa postura é defendida por José de Alencar, Mattoso Câmara e Nelson Rossi, por exemplo. O autor inclui a NGB, que visa dar unidade terminológica às gramáticas escolares adotadas no Brasil, e os estudos atuais sobre a língua portuguesa. O segundo recorte refere-se aos estudos que visam uma unidade linguística Portugal/Brasil (atitude purista, classicista). Fazem parte deste os estudiosos que defendem o modelo clássico no início do século $\mathrm{XX}$, os gramáticos atuais que trabalham com textos clássicos e canônicos e ações como os acordos ortográficos.

A partir dos recortes acima, o autor estabelece mais dois: um diz respeito aos trabalhos que não apresentam um aporte teórico bem definido (João Ribeiro, a NGB etc.), outro focaliza as produções com um aporte teórico definido (Said Ali, Mattoso Câmara, os estudos da pós-graduação).

Conforme os argumentos arrolados, o desenvolvimento e a valorização do discurso gramatical estão diretamente relacionados à constituição de uma língua nacional, a fim de gerar um imaginário de unidade linguística: "enquanto língua do Estado e língua nacional, o português dispõe de instrumentos específicos de organização do espaço de enunciação: a Escola, a gramática e o dicionário. A estas se junta de maneira decisiva hoje a mídia" (GUIMARÃES, 2006, p. 49). Em nossas análises, articulamos tais pressupostos às noções da Análise de Discurso de linha francesa (de viés pecheutiano), discutidas na seção seguinte.

\section{Discurso, sentido e ideologia: princípios teóricos}

Interessa à Análise de Discurso a língua em sua forma material (linguístico-histórica). Por ter uma materialidade constitutiva, ela não é transparente. Por conseguinte, o sentido das palavras não é obvio. As palavras não se referem de forma unívoca e clara às coisas do mundo. Há sempre a possibilidade do equívoco, pois a língua está sujeita a falhas. De acordo Orlandi (2007b, 2012), o equívoco é definido como o permanente confronto entre o real da língua e o real da história - " [...] o 
sistema [linguístico] é um sistema significante, capaz de falhas, que, para cumprir-se em seu desígnio de significar, é afetado pelo real da história" (ORLANDI, 2012, p. 40). A língua se inscreve na história para significar. Ela é o aspecto material do discurso; este, o aspecto material da ideologia.

Conforme a autora, pelo fato de a língua não ser transparente, existe uma injunção à interpretação. Os fatos reclamam sentidos, e os sujeitos estão condenados a significar. Entretanto, não controlamos o modo pelo qual somos afetados pelos sentidos. Isto posto, Pêcheux (2009 [1975]) afirma que o discurso é efeito de sentido entre locutores. Para ele, um enunciado se relaciona com uma série de outros enunciados heterogêneos, os quais funcionam a partir de diferentes registros discursivos e uma estabilidade variável.

Os discursos se constituem a partir de determinadas condições de produção, que implicam a situação imediata em que o discurso é produzido, os sujeitos envolvidos e o contexto mais amplo, ou seja, as condições sócio-históricas e ideológicas. Nessa perspectiva, levamos em conta as formações imaginárias, que se constituem pelas relações de sentido, pelos mecanismos de antecipação e pelas relações de força (ORLANDI, 2009). As relações de sentidos dizem respeito ao fato de um discurso sempre apontar para discursos anteriores que o sustentam, como também para dizeres futuros. Não há discurso que não se relacione com outros:

Todo discurso é visto como um estado de um processo discursivo mais amplo, contínuo. Não há, desse modo, começo absoluto nem ponto final para o discurso. Um dizer tem relação com outros dizeres realizados, imaginados ou possíveis (ORLANDI, 2009, p. 39).

Os mecanismos de antecipação, por sua vez, dirigem o processo de argumentação. O sujeito tem a capacidade de colocar-se imaginariamente no lugar do outro, de seu interlocutor, fazendo com que ele enuncie de um dado modo, de acordo com o efeito que ele pensa produzir em seu interlocutor. Já o terceiro fator, as relações de força, refere-se ao princípio de que "o lugar do qual fala o sujeito é constitutivo do que ele diz” (ORLANDI, 2009, p. 39). Como nossa sociedade é constituída por relações hierarquizadas, as relações de força se sustentam na imagem do poder de diferentes lugares, como o de professor, aluno etc., as quais lhes são conferidos determinados valores. 
Como o nome já aponta, o objeto da Análise de Discurso é o discurso, e sua unidade de análise, o texto em suas diversas materialidades (verbal, não-verbal). É neste que o discurso se materializa. É a partir dele que temos acesso ao discurso. Sendo um objeto linguístico-histórico, o analista busca averiguar como o texto funciona, como ele produz sentidos. O texto é uma unidade imaginária com um início, meio e fim que o analista tem diante de si para analisar a produção de sentidos. Sobre esta questão, Orlandi (2012, p. 67) declara:

O texto mostra como se organiza a discursividade, isto é, como o sujeito está posto, como ele está significado sua posição, como a partir de suas condições (circunstâncias da enunciação e memória) ele está praticando a relação do mudo com o simbólico, materializando sentidos, textualizando, formulando, breve, 'falando'.

O processo de produção do discurso, de acordo com a autora, implica três momentos importantes. O primeiro, a constituição, referese ao contexto histórico-ideológico mais amplo, à memória do dizer. A formulação, segundo momento, diz respeito às condições de produção, às circunstâncias específicas da enunciação. É na formulação do discurso que a memória se atualiza, a linguagem adquire vida, os sentidos são decididos e os sujeitos se evidenciam. Já o terceiro momento, a circulação, é tão importante quanto os dois primeiros. Ela acontece em uma determinada conjuntura e segundo certas condições. Os meios nunca são neutros.

Desse modo, é a ideologia que interpela os indivíduos em sujeitos, produzindo um efeito de evidência, como se os sujeitos e os sentidos existissem em si, sustentando-se no já-dito, nos sentidos institucionalizados admitidos como "naturais". Ela não é a ocultação da realidade, e sim a condição necessária para a existência da relação entre mundo e linguagem, sendo, portanto, fundamental para a constituição dos sentidos e dos sujeitos. Orlandi afirma (2007b, p. 31): "A ideologia é interpretação de sentido em certa direção, direção determinada pela relação da linguagem com a história e seus mecanismos imaginários". Ainda segundo a autora: "Estando os sujeitos condenados a significar, a interpretação é sempre regida por condições de produção específicas que, no entanto, aparecem como universais e eternas, daí resultando a impressão do sentido único e verdadeiro" (ORLANDI, 2007a, p. 96). 
O sujeito, para a Análise de Discurso, não é uma entidade empírica, e sim uma posição entre outras que pode ser ocupada. Segundo a autora,

Pensando-se a subjetividade, podemos então observar os sentidos possíveis que estão em jogo em uma posiçãosujeito dada. Isso porque, como sabemos, o sujeito, na análise do discurso, é posição entre outras, subjetivandose na medida mesmo em que se projeta de sua situação (lugar) no mundo para sua posição no discurso. Essa projeção-material transforma a situação social (empírica) em posição sujeito (discursiva) (ORLANDI, 1999, p. 1).

A subjetivação é, portanto, para a autora, uma questão de qualidade: não é possível a quantificação do assujeitamento. Não se é menos ou mais sujeito. Vale ressaltar que um dos fundamentos básicos da Análise de Discurso é que não existe sentido sem sujeito, nem sujeito sem ideologia. Como os sentidos não são dados, e os sujeitos não estão na origem deles, a perspectiva discursiva defende que eles são constituídos nas formações discursivas. Noção utilizada incialmente por Foucault em A arqueologia do saber (1969) e retomada por Pêcheux (2009 [1975]), na segunda fase da elaboração da teoria materialista do discurso. Pêcheux não a importou apenas, ele a interpretou e reelaborou. Para ele,

[...] as palavras, expressões, proposições etc., mudam de sentido segundo as posições sustentadas por aqueles que as empregam, o que quer dizer que elas adquirem seu sentido em referência a essas posições, isto é, em referência às formações ideológicas [...] nas quais essas posições se inscrevem. Chamaremos formação discursiva aquilo que, numa conjuntura dada, determinada pelo estado da luta de classes, determina o que pode e deve ser dito [....]. Isso equivale a afirmar que as palavras, expressões, proposições etc., recebem seu sentido da formação discursiva na qual são produzidas (PÊCHEUX, 2009 [1975], p. 146-147).

Os sentidos se constituem na inscrição do sujeito em múltiplas formações discursivas (regiões do dizível), as quais são determinadas por formações ideológicas. Estas são definidas por Pêcheux e Fuchs (2010 [1975]) como um conjunto complexo de atitudes e de representações que não são nem individuais nem universais, pois estão ligadas mais ou 
menos às posições de classes. As relações entre as diversas formações discursivas são reguladas historicamente, constituindo os diferentes efeitos de sentidos entre locutores. Orlandi (2007a, p. 1) defende que "[...] a formação discursiva é heterogênea em relação a ela mesma, pois já evoca por si o 'outro' sentido que ela não significa”. A autora acrescenta ainda:

As formações discursivas são diferentes regiões que recortam o interdiscurso (o dizível, a memória do dizer) e que refletem as diferenças ideológicas, o modo como as posições dos sujeitos, seus lugares sociais aí representados, constituem sentidos diferentes. O dizível (o interdiscurso) se parte em diferentes (as diferentes formações discursivas) desigualmente acessíveis aos diferentes locutores (ORLANDI, 2007a, p. 20).

As formações discursivas recortam o interdiscurso (a memória do dizer, o já-dito). Este é compreendido como a exterioridade constitutiva do nosso dizer: "[...] todo enunciado é tomado em uma série de enunciados, que pertencem a outras sequências discursivas emitidas anterior ou simultaneamente, e que constituem sua condição de existência" (PÊCHEUX; FUCHS, 2010 [1975], p. 277).

O intradiscurso (eixo da formulação) supõe a ocupação de lugares determinados em formações discursivas. Já o interdiscurso (eixo da constituição) permite a repetição, o esquecimento, o apagamento ou a denegação dos elementos de saber de uma dada formação discursiva. É ele que regula o deslocamento das fronteiras das formações discursivas que se encontram em embate (contradição, aliança etc.). Consoante Orlandi (2012, p. 14): "O discurso é um processo contínuo que não se esgota em uma situação particular. Outras coisas foram ditas antes e outras serão ditas depois. O que temos são sempre 'pedaços', 'trajetos', estados do processo discursivo".

Por conseguinte, os sentidos não são fixados a priori como essência das palavras, nem tampouco podem ser qualquer um, por sua determinação histórica. São administrados (geridos) nas/pelas instituições, levando em conta as diferentes posições dos sujeitos (pai, professor, patrão etc.), as diferentes instituições (igreja, família, partido etc.), e pela grande produção de textos (livros, regulamentos, programas de partido etc.). 
A partir desse quadro teórico, a seguir discutimos sobre o modo de funcionamento da posição-sujeito gramático ocupada por Evanildo Bechara na mídia.

\section{A posição-sujeito ocupada por Evanildo Bechara: "um dos mais respeitados especialistas da língua portuguesa"}

Como observamos acima, recusando a concepção idealista de sujeito (homogêneo, origem do dizer), a perspectiva discursiva questiona a autonomia do sujeito, asseverando que sua constituição se dá ao mesmo momento da constituição dos sentidos. O sujeito é uma posição discursiva entre outras inscrita em determinadas formações discursivas que, por sua vez, são determinadas pelas formações ideológicas. Logo, o que se diz não é dito de qualquer lugar, em qualquer circunstância. Cabe-nos questionar como funciona a posição-sujeito assumida pelo gramático Evanildo Bechara na mídia. Será que é a mesma do século XIX, ocupada pelos primeiros gramáticos brasileiros? Enquanto posição discursiva, ele mantém um discurso purista pautado no tradicionalismo ou há um deslizamento para uma posição científica, levando em consideração os "avanços" dos estudos linguísticos?

Para a constituição de nosso corpus, foram selecionadas 10 peças textuais, entrevistas com o gramático Evanildo Bechara, que dizem respeito ao debate sobre a gramática e a língua (estabelecimento do acordo ortográfico, questões sobre o ensino de língua etc.).

Sobre o gênero discursivo entrevista, em seu modelo canônico, tem-se uma estrutura geral marcada por perguntas e respostas, porém manifesta estilos e propósitos diversos, tais como: entrevista jornalística, entrevista científica, entrevista médica etc. Este gênero "é composto de, pelo menos, dois indivíduos, cada um com seu papel específico: o entrevistador, responsável pelas perguntas, e o entrevistado, responsável pelas respostas" (HOFFNALGEL, 2010, p. 196), os quais ocupam geralmente, papéis institucionalizados. Em seu funcionamento, a entrevista é primordialmente um gênero oral. Quando publicada em jornais e revistas, na maioria das vezes, acontece a transcrição do oral para o escrito e é efetuado um recorte do material coletado. Todas as entrevistas aqui analisadas encontram-se na internet de forma escrita.

Cronologicamente, os textos selecionados são: 
QUADRO 1

Entrevistas selecionadas

\begin{tabular}{|l|c|c|}
\hline \multicolumn{1}{|c|}{ Título da entrevista } & Suporte de circulação & $\begin{array}{c}\text { Data de } \\
\text { publicação }\end{array}$ \\
\hline Entrevista com Evanildo Bechara & Revista Philologus & 23 fev. 2005 \\
\hline $\begin{array}{l}\text { Gramático Evanildo Bechara defende novo } \\
\text { acordo ortográfico }\end{array}$ & Folha de São Paulo & 29 dez. 2008 \\
\hline $\begin{array}{l}\text { Entrevista: gramático defende que reforma } \\
\text { ortográfica torna escrita mais simples }\end{array}$ & A Tarde & 12 mar. 2009 \\
\hline Entrevista: Evanildo Bechara & Rubens Andrade.com & 16 nov. 2010 \\
\hline Evanildo Bechara: o mestre das letras & O Povo & 13 dez. 2010 \\
\hline $\begin{array}{l}\text { O aluno não vai para a escola para aprender } \\
\text { "nós pega o peixe" }\end{array}$ & Último Segundo & 13 maio 2011 \\
\hline Senhor Norma Culta & Revista Piaúi & jun. 2011 \\
\hline Em defesa da gramática & Veja & $1^{\circ}$ jun. 2011 \\
\hline $\begin{array}{l}\text { "Com acordo, tiramos um peso dos } \\
\text { ombros”, diz Evanildo Bechara }\end{array}$ & Estadão & 12 nov. 2012 \\
\hline Evanildo Bechara & SESC SP & 01 fev. 2013 \\
\hline
\end{tabular}

Iniciamos nossas análises retomando a distinção dos recortes do modo de organização histórica dos estudos sobre o português no Brasil proposta por Guimarães (1996a). Enquanto um primeiro recorte visa evidenciar (de forma contrastiva ou não) a especificidade do português brasileiro do de Portugal, um segundo recorte defende uma unidade linguística Brasil/Portugal. Fazem parte desse recorte os estudiosos que defendem o modelo clássico do século XX e os gramáticos atuais, os quais trabalham com textos clássicos e canônicos. O gramático Evanildo Bechara enquadra-se no segundo recorte. Existe uma identificação com redes de sentidos que "defendem" uma unidade linguística entre os países de língua portuguesa. Além disso, da posição-sujeito gramático que ele se identifica, é defendida ferrenhamente a leitura e adoção de textos clássicos pelos professores de língua materna, afirmando que a falta de leitura desses textos é uma das principais razões para a "deficiência" do ensino do português. Vejamos algumas sequências discursivas: 
(1) “ $O P-\mathrm{O}$ ensino do português brasileiro não se confunde com o ensino do português europeu? Ou o senhor não gosta de fazer essa distinção?

Bechara - Na realidade, não. É como se você quisesse fazer a distinção entre você, cearense, e membros da sua família. Existiu um filósofo alemão que disse que a língua era mais forte que o sangue" (O povo, 2010).

(2) "O ensino do português nas escolas é deficiente. Uma das razões recai sobre o evidente despreparo dos professores. [...] Além disso, não detêm uma cultura geral muito ampla nem tampouco costumam ler os grandes autores, como faziam os antigos mestres" (Veja, 2011, p. 25).

Em (1), observamos a significação da língua enquanto naturalidade, característica biológica. A unidade linguística Brasil/Portugal é, então, preponderante em relação aos aspectos que diferenciam a língua aqui falada e escrita da língua europeia. Não é observado que as línguas funcionam de acordo com a sua distribuição para os falantes, que é política, desigual. O enquadramento de Evanildo Bechara no segundo recorte pode ser corroborado ainda pelo fato da defesa à adoção do acordo ortográfico elaborado em 1990. Nos textos em análise, o lugar ocupado pelo gramático evidencia que a padronização ortográfica do português pode contribuir para o seu fortalecimento da identidade linguística e político-econômica no cenário internacional:

(3) "O acordo ortográfico da língua portuguesa quando ele foi imaginado ele tinha como objetivo facilitar a educação, hoje ele não só continua facilitando a educação escrita, mas também é um dos instrumentos importantes para divulgação da língua no mundo" (RubensAndrade.com, 2010).

Estando à frente da adoção do acordo ortográfico, a posiçãosujeito assumida pelo gramático é revestida pelos sentidos institucionais advindos da Academia Brasileira de Letras. Ao recortar o interdiscurso, o sujeito inscreve-se em uma formação discursiva marcada pela concepção de uma língua portuguesa unitária entre os países que a falam. Conforme Orlandi (2012, p. 10): 
Não há corpo que não seja investido de sentidos e que não seja o corpo de um sujeito que se constitui por processo de subjetivação nos quais as instituições e suas práticas são fundamentais, assim como o modo pelo qual, ideologicamente, somos interpelados em sujeitos.

Nesse ponto, vale ressaltar a importância do funcionamento da escrita. O que deve ser ensinado na escola e reforçado pela mídia é a norma culta: aquela utilizada por escritores consagrados como Machado de Assis. A gramática e a escrita encontram-se imbricadas. Sobre este fato, Auroux (1998) pondera que a gramática depende da razão gráfica, uma vez que são classificados os elementos de uma língua. $\mathrm{O}$ próprio da gramática é estabelecer fronteiras entre as partes do discurso (substantivos, adjetivos, verbos etc.) e entre variedades linguísticas (distinguir o "bom português" daquilo que não o é).

Nos textos em análise, o gramático é significado como a "autoridade máxima" quando se trata das discussões envolvendo a língua, no que diz respeito não só à gramática, mas também ao ensino do português, aos acordos estabelecidos entre os países de língua portuguesa para a unificação ortográfica etc. Consoante Geraldi (1993), nas sociedades contemporâneas, instituições como a escola e a mídia definem os sujeitos competentes para falar sobre determinados assuntos, observando sua especialidade. Ao tratar de questões relacionadas à gramática e ao ensino de língua materna, por sua importância na constituição de uma língua nacional e por defender o "bom português", a posição-sujeito gramático é dominante na mídia. Vejamos o enunciado (4):

(4) "O pernambucano Evanildo Bechara é um dos mais respeitados gramáticos da língua portuguesa. Doutor em letras e autor de duas dezenas de livros, entre os quais a consagrada Moderna Gramática Portuguesa, Bechara, de 83 anos, passou décadas ensinando português" (Veja, 2011, p. 21).

Nos lides das entrevistas, temos uma contextualização do assunto tratado, e uma pequena apresentação do entrevistado. Nelas podemos observar como o gramático e a gramática são significados. Vejamos: 
(5) "Um dos mais respeitados especialistas da língua portuguesa condena os colegas que se insurgem contra a norma culta - e diz que disseminá-la é crucial para o país avançar" (Veja, 2011, p. 21).

(6) "Imortal da Academia Brasileira de Letras diz que língua familiar é aceita do ponto de vista linguístico, mas não deve ser ensinada" (Último Segundo, 2011).

Retomando a noção de formação imaginária, nos enunciados acima arrolados, verificamos como os autores dos textos apresentam o gramático e como este concebe o ensino de gramática, a qual adquire o sentido correlato à língua portuguesa. As qualificações que significam o gramático colaboram para a imagem de defensor da língua portuguesa. O gramático é o responsável pelo discurso sobre a língua e a gramática, administrando os sentidos. Posição imputada historicamente a esse tipo de sujeito.

Pelos mecanismos de antecipação, é possível analisar o direcionamento das questões propostas ao entrevistado, de acordo com as representações dominantes do que é um gramático e de quais assuntos esse sujeito pode tratar com autoridade. Em alguns casos, chegam até a defender um ponto de vista nas perguntas.

(7) “A defesa que o livro Por uma Vida Melhor, distribuído a 500 000 estudantes ao custo de milhões de reais para o bolso dos brasileiros, faz do uso errado da língua deveria ter provocado uma revolta maior, não?" (Veja, 2011, p. 21).

O gramático responde:

(8) “A defesa que foi feita desse livro decorre de um equívoco. Estão confundindo um problema de ordem pedagógica, que diz respeito às escolas, com uma velha discussão teórica da sociolinguística, que reconhece e valoriza o linguajar popular" (Veja, 2011, p. 21).

Em (7) e (8), mais uma vez, verificamos os sentidos de "defesa". No enunciado (7), o sujeito enunciador parte de uma constatação: “o livro faz uso errado da língua". Esse imaginário de erro é constitutivo. Os sentidos do não questionamento é um efeito do pré-construído, definido 
por Pêcheux (2009 [1975], p. 198) como “o ‘sempre-já aí' da interpelação ideológica que fornece-impõe a 'realidade e seu 'sentido' sob a formada universalidade - o "mundo das coisas"". A dicotomia entre "certo" e "errado" é constitutiva de nossa memória discursiva. Vale ressaltar que esta divisão se origina dos estudos gramaticais na Antiguidade GrecoRomana. No tocante ao discurso sobre a gramática e a língua portuguesa, é naturalizado que devemos seguir, à risca, as normas que constituem a gramática normativa para sermos "bons cidadãos", "bons sujeitos".

Nas entrevistas, a imagem construída dos linguistas é:

(9) “Agora, um grupo de brasileiros tenta repetir essa mesma lógica equivocada, empenhando-se em desvalorizar o bom português" (Veja, 2011, p. 24, grifo nosso).

(10) "Diz Bechara: 'Alguns de meus colegas subvertem a lógica que só serve para tirar de crianças e jovens a chance de ascenderem socialmente"" (Veja, 2011, p. 21, grifo nosso).

(11) "A linguagem popular que alguns colegas meus se referem, por sua vez, não apresenta vocabulário nem tampouco estrutura gramatical que permita desenvolver ideias de maior complexidade - tão caras a uma sociedade que almeja evoluir" (Veja, 2011, p. 21-24, grifo nosso).

São utilizados pronomes indefinidos para referir-se aos linguistas, colocando-os em um lugar inferior. Na Gramática escolar da língua portuguesa, Evanildo Bechara assevera que os pronomes indefinidos "são os que se aplicam à $3^{\mathrm{a}}$ pessoa quanto têm sentido vago ou exprimem quantidade indeterminada" (BECHARA, 2006, p. 138). Mesmo trabalhando com conceitos da Linguística, o gramático identifica-se com uma posição-sujeito que assume uma divisão entre aqueles que defendem a língua portuguesa (em seu bom uso) daqueles que aceitam tudo. Os enunciados "Um grupo" e "alguns (de meus) colegas" podem ser substituídos por "poucos", "uma minoria".

A posição-sujeito assumida pelo gramático apoia-se no logicismo fundado pelas gramáticas gerais e arrazoadas, que tomam como base, principalmente, os fundamentos da Gramática de Port-Royal, dos franceses Arnauld e Lancelot (1660). Sobre essa relação, observando que é dessa tradição que são as gramáticas tomadas para o ensino de língua 
aqui no Brasil, Bueno (1958, p. 247) argumenta: "grande e desastrosa consequência de tais ideias filosóficas é o ensino intensivamente absurdo de tal análise lógica, análise sintática das orações, que tem sido a ruína do aprendizado idiomático, quer aqui, quer em Portugal".

Ainda no que diz respeito aos sentidos da lógica, Pêcheux (2012 [1983], p. 34) afirma que nós, enquanto sujeitos pragmáticos, possuímos uma "imperiosa necessidade lógica", sendo que "essa necessidade de um 'mundo semanticamente normal', isto é, normatizado, começa com a relação de cada um com seu próprio corpo e seus arredores imediatos". Para o autor, são as evidências lógico-práticas que unificam os espaços discursivos. A gramática e a língua são significadas como um "espaço discursivo logicamente estabilizado" (PÊCHEUX, 2012 [1983]).

Os linguistas, dessa forma, são significados como sujeitos que buscam "subverter a lógica", ou possuem uma "lógica equivocada". A partir da posição-sujeito ocupada pelo gramático, os linguistas deveriam manter seus estudos somente na universidade.

(12) "As teorias da sociolinguística jamais deveriam ter deixado as fronteiras da academia. Nas escolas, elas só reduzem as chances de os estudantes aprenderem o bom português" (Veja, 2011, p. 24).

Tomado pelos sentidos do discurso dos estudos linguísticos, é observado que não há somente uma língua portuguesa ou uma única "modalidade linguística". As contribuições da Linguística não são negadas. Porém, a escola deve ensinar somente a norma culta para que os estudantes obtenham "sucesso no âmbito pessoal e profissional". Sem abandonar a tradição gramatical, a caução da Linguística (ciência) é requerida para inscrever o trabalho gramatical no lugar dos "avanços dos estudos linguísticos". No prefácio da atual edição (37ª da Moderna gramática do português, por exemplo, os sentidos advindos dos estudos linguísticos recortam a materialidade linguística:

(13) "Amadurecido pela leitura atenta dos teóricos da linguagem, da produção acadêmica universitária, das críticas e sugestões gentilmente formuladas por companheiros da mesma seara e da leitura demorada de nossos melhores escritores, verá facilmente o leitor que se trata aqui de um novo livro" (BECHARA, 2009, p. 19). 
Nessa perspectiva, estamos compreendendo os sentidos desses "avanços" enquanto uma exterioridade constitutiva que afeta o sujeito e o faz funcionar. O objeto posto em debate (a gramática/a língua) é direcionado pela disputa entre os interlocutores. Os sentidos postos em circulação encontram-se em um equilíbrio tenso entre a paráfrase e a polissemia. Como mencionado acima, os sentidos da gramática, norma culta etc., são administrados nessa relação conflituosa entre o "tradicionalismo" e os "avanços". Esse embate entre discursividades é textualizado de forma significativa nas entrevistas. Há uma busca do afastamento da imagem do gramático enquanto "conservador" e o linguista como "libertário".

(14) "Consolidaram-se processo histórico, assim, estereótipos. Enquanto o linguista era vinculado à ideia de liberdade, o gramático simbolizava a opressão. Todo o falar seria legítimo, não existiria certo e errado, desde que o falante se faça entender. A correção seria uma violência a jeitos diferentes de falar do aluno" (Revista Piauí, 2011).

Em (14), Bechara se coloca como analista do ponto de vista histórico. Busca-se um deslocamento de sentidos que, dessa posiçãosujeito, constituem a identidade (estereotipada) do gramático e do linguista. Vale lembrar que o estereótipo é uma representação coletiva cristalizada. Ele está ligado, então, ao pré-construído (sempre-já aí). Destarte, podemos constatar que a posição-sujeito ocupada por Evanildo Bechara está diretamente ligada aos sentidos institucionais (gramático, professor, membro da ABL) que lhe conferem legitimidade e poder ao seu discurso. Ele enuncia sobre os avanços dos estudos linguísticos a partir do lugar da tradição gramatical.

\section{Considerações finais}

Ao longo do presente trabalho, buscamos compreender a posiçãosujeito ocupada pelo gramático Evanildo Bechara em entrevistas postas em circulação pela mídia nacional. Observamos que a constituição do sujeito em questão acontece de forma contraditória. Existe uma tensão ideológica entre os sentidos dos "avanços" dos estudos linguísticos e os sentidos da tradição gramatical. Ao enunciar sobre questões concernentes à gramática, ao ensino de língua materna, à implementação do acordo 
ortográfico etc., o sujeito ocupa uma posição-sujeito que, por um lado, reafirma uma análise lógica da língua, sendo o português dividido entre "bom" e "mau"; por outro, o gramático é tomado pelas discussões da Linguística, requerida para conferir cientificidade ao seu dizer.

Ao recortar três, dos quatros períodos do processo de gramatização definidos por Guimarães (1996a), Evanildo Bechara identifica-se com formações discursivas que reatualizam a tradição gramatical lógicofilosófica (gramáticas gerais e arrazoadas), da qual faz parte a famosa gramática de A. Arnauld e Cl. Lancelot, a Gramática de Port Royal (1690) que, por sua vez, remonta aos estudos greco-latinos. Estes, com base na lógica, centravam-se na teoria do "certo" versus "errado", privilegiando a escrita.

O sujeito gramático Evanildo Bechara é, assim como os sentidos, construído em uma tensão posta pelo jogo entre uma tradição gramatical, oriunda da antiguidade greco-latina e análise lógica, que busca um "bom" falar e escrever; e os sentidos dos "avanços" dos estudos linguísticos, que funcionam como uma exterioridade constitutiva. Para significar enquanto "moderno", o gramático é tomado pelas discussões postas pela Linguística, a ciência capaz de dizer como a língua funciona e que, consequentemente, dá caução ao dizer do gramático. Há, então, um embate entre discursividades textualizado de forma significativa nas entrevistas, por uma busca do afastamento da imagem do gramático enquanto "conservador" e o linguista como "libertário". No entanto, reafirmam-se outras imagens, como a do gramático "defensor", e a do linguista que "aceita tudo".

Nas entrevistas, a materialidade que nos deu acesso ao discurso, é reiterada a posição de "defesa" dos gramáticos, sócio-historicamente construída. Esses sentidos de "defesa" da gramática, da língua portuguesa e do acordo ortográfico estão atrelados à constituição de uma unidade linguística. Aqui no Brasil, é a partir da segunda metade do século XIX, depois da Independência do Estado nacional, com a publicação das primeiras gramáticas de autoria brasileira, que se busca um afastamento do saber metalinguístico português. Defende-se, então, a língua nacional, a identidade linguística e cidadã dos seus sujeitos falantes, a pátria.

Destacamos também a importância dos sentidos institucionais para a construção de imagens de um gramático respeitado. $\mathrm{O}$ caráter institucional da posição-sujeito assumida por Evanildo Bechara é revestido por sua ocupação da cadeira de número 33, na Academia 
Brasileira de Letras. Por ser considerado um imortal, sua autoridade frente a questões sobre a gramática e a língua é evidenciada. Por meio da análise de matérias sobre o gramático e dos títulos das entrevistas, por exemplo, podemos averiguar a produção de sentidos que enobrecem a significação de tal sujeito como "um dos mais respeitados" gramáticos e "especialistas" da língua portuguesa.

\section{Referências}

AUROUX, Sylvain. A filosofia da linguagem. Trad. José Horta Nunes. Campinas, SP: Editora da Unicamp, 1998. p. 63-96.

AUROUX, Sylvain. (1992). A revolução tecnológica da gramatização. Trad. de Eni Puccinelli Orlandi. 2. ed. Campinas, SP: Editora da Unicamp, 2009.

BALDINI, Lauro. A NGB e a autoria no discurso gramatical. Língua e instrumentos linguísticos, Campinas/SP: Pontes, n. 1, p. 97-107, 1998.

BECHARA, Evanildo. Gramática escolar da língua portuguesa. 1. ed. 6. reimpr. Rio de Janeiro: Lucerna, 2006.

BUENO, Francisco da Silveira. A formação da língua portuguesa. 2. ed. Rio de Janeiro: Livraria Acadêmica, 1958.

FÁVERO, Leonor Lopes. Gramática é a arte... In: ORLANDI, Eni Puccinelli (Org.). História das ideias linguísticas: construção do saber metalinguístico e constituição da língua nacional. Campinas, SP: Pontes, 2001. p. 59-70.

FÁVERO, Leonor Lopes. A gramática luso-brasileira e o método científico. Filologia e linguística portuguesa, n. 9, p. 27-42, 2007.

GERALDI, João Wanderley. Portos de passagem. São Paulo: Martins Fontes, 1993.

GUIMARÃES, Eduardo. Sinopse dos estudos do português no Brasil: a gramatização brasileira. In: GUIMARÃES, Eduardo; ORLANDI, Eni Puccinelli (Org.). Língua e cidadania: o português no Brasil. Campinas: Pontes, 1996a. p. 127-138. 
GUIMARÃES, Eduardo; ORLANDI, Eni Puccinelli. Identidade linguística. In: ___ _ ORLANDI, Eni Puccinelli (Org.). Língua e cidadania: o português no Brasil. Campinas: Pontes, 1996b. p. 9-15.

GUIMARÃES, Eduardo. Enunciação e política de língua no Brasil. Revista Letras: espaços de circulação da linguagem, n. 27, p. 47-53, jul.dez. 2006.

HOFFNAGEL, Judith Chambliss. Entrevista: uma conversa controlada. In: DIONÍSIO, Angela Paiva; MACHADO, Anna Rachel; BEZERRA, Maria Auxiliadora (Org.). Gêneros textuais e ensino. São Paulo: Parábola Editorial, 2010. p. 195-208.

ORLANDI, Eni Puccinelli. Do sujeito na história e no simbólico. Escritos, n. 4, 1999.

ORLANDI, Eni Puccinelli. O Estado, a gramática, a autoria: língua e conhecimento linguístico. Línguas e instrumentos linguísticos, Campinas, n. 4/5, p. 19-34, 2000a.

ORLANDI, Eni Puccinelli. Metalinguagem e gramatização no Brasil: gramática-filologia-linguística. Rev. ANPOLL, n. 8, p. 29-39, jan.-jun. $2000 \mathrm{~b}$.

ORLANDI, Eni Puccinelli; GUIMARÃES, Eduardo. Formação de um espaço de produção linguística: a gramática no Brasil. In: ORLANDI, Eni Puccinelli (Org.). História das ideias linguísticas: construção do saber metalinguístico e constituição da língua nacional. Campinas, SP: Pontes, 2001. p. 21-38.

ORLANDI, Eni Puccinelli. As formas do silêncio: no movimento dos sentidos. 6. ed. Campinas, SP, Editora da Unicamp, 2007a.

ORLANDI, Eni Puccinelli. Interpretação: autoria, leitura e efeito do trabalho simbólico. 5. ed. Campinas, SP: Pontes Editores, $2007 \mathrm{~b}$.

ORLANDI, Eni Puccinelli. Análise de Discurso: princípios e procedimentos. 8. ed. São Paulo: Pontes, 2009.

ORLANDI, Eni Puccinelli. Discurso e texto: formulação e circulação dos sentidos. 4. ed. Campinas, SP: Pontes Editores, 2012.

PÊCHEUX, Michel. (1975). Semântica e discurso: uma crítica à afirmação do óbvio. Trad. de Eni Puccinelli Orlandi et al. 4. ed. Campinas: Editora da Unicamp, 2009. 
PÊCHEUX, Michel; FUCHS, Catherine. (1975). A propósito da análise automática do discurso: atualização e perspectiva. In: GADET, Françoise. HAK, Tony. (Org.). Por uma análise automática do discurso: uma introdução à obra de Michel Pêcheux. 4. ed. Campinas: Editora da Unicamp, 2010. p. 159-249.

PÊCHEUX, Michel. (1983). O discurso: estrutura ou acontecimento. Trad. Eni Puccinelli Orlandi. 5. ed. Campinas, SP: Pontes Editores, 2012.

\section{Entrevistas analisadas}

A TARDE. Entrevista: gramático defende que reforma ortográfica torna escrita mais simples. Salvador/BA, 12 mar. 2009. Entrevista a Içara Bahia. Disponível em: <http://atarde.uol.com.br/cultura/materias/1088381entrevista:-gramatico-defende-que-reforma-ortografica-torna-escritamais-simples>. Acesso em: 02 abr. 2013.

ESTADÃO. “Com o acordo, tiramos um peso dos ombros", diz Evanildo Bechara. São Paulo, 12 nov. 2012. Disponível em: $<$ http://www.estadao. com.br/noticias/arteelazer,com-o-acordo-tiramos-um-peso-dos-ombrosdiz-evanildo-bechara,959220,0.htm>. Acesso em: 15 jun. 2013.

FOLHA DE SÃO PAULO. Gramático Evanildo Bechara defende novo acordo ortográfico. São Paulo, 29 dez. 2008. Entrevista a Sylvia Colombo. Disponível em: <http://www1.folha.uol.com.br/folha/ ilustrada/ult90u484105.shtml>. Acesso em: 2 abr. 2013.

O POVO ONLINE. Evanildo Bechara: o mestre das letras. Fortaleza/Ce, 13 dez. 2010. Disponível em: <http:/www.opovo.com.br/app/opovo/ paginasazuis/2010/12/13/noticiasjornal paginasazuis,2077172/evanildobechara-o-mestre-das-letras.shtml>. Acesso em: 2 abr. 2013.

PHILOLOGUS. Entrevista com Evanildo Bechara. 2005. Entrevista a Vito Manzolillo. Disponível em: <http://www.filologia.org.br/revista/ artigo/11(31)entrevista.htm>. Acesso em: 5 mar. 2013.

PIAUÍ. Senhor norma culta. Piauí, 57. ed., jun. 2011. Entrevista a Clara Becker. Disponível em: <http://revistapiaui.estadao.com.br/edicao-57/ questoes-vernaculas/senhor-norma-culta>. Acesso em: 29 mar. 2013. 
RUBENS ANDRADE.COM. Entrevista: Evanildo Bechara., 16 nov. 2010. Entrevista a equipe do site Rubens Andrade. Disponível em: $<$ http:// www.rubensandrade.com.br /noticias/trabalho-parlamentar/entrevistaevanildo-bechara/>. Acesso em: 2 fev. 2014.

SESC-SP. Evanildo Bechara. 01 fev. 2013. Disponível em: $<$ http:// www.sescsp.org.br/online/artigo/6698_EVANILDO+BECHARA\#/ tagcloud=lista $>$. Acesso em: 4 jan. 2014.

VEJA. Em defesa da gramática. São Paulo, p. 21-25. 01 jun. 2011. Entrevista a Roberta de Abreu Lima. Disponível em: $<$ http://veja.abril. com.br/acervodigital/home.aspx? cod= JNJMKQDQQRM>. Acesso em: 24 jan. 2014.

ÚLTIMO SEGUNDO. O aluno não vai para a escola para aprender "nós pega o peixe". São Paulo, 13 mai. 2011. Entrevista a Thais Arbex. Disponível em: <http://ultimosegundo.ig.com.br/educacao/ $\mathrm{o}+$ aluno+nao+vai + para $+\mathrm{a}+$ escola + para + aprender + nos + pega $+\mathrm{o}+$ peixe/ n1596951472448.html>. Acesso em: 21 ago. 2013. 